\title{
Aplicação de suspensões de Agaricus blazei, Lentinula edodes e de acibenzolar-S-metil na redução da antracnose em frutos de maracujá-azedo
}

\author{
Danila S.O. Coqueiro ${ }^{1}$, Cleiltan N. Silva ${ }^{2}$, Carlos Bernard M. Cerqueira-Silva ${ }^{1}$, Gaus S.A. Lima ${ }^{3}$, Armínio \\ Santos $^{4}$ \& Antonio C. Oliveira ${ }^{5}$ \\ ${ }^{1}$ Instituto de Biologia, Universidade Estadual de Campinas, 13083-862, Campinas, SP, Brasil; ${ }^{2}$ Departamento de Agronomia, \\ Universidade Estadual de Maringá, 87020-900 Maringá, PR, Brasil; ${ }^{3}$ Centro de Ciências Agrárias, Universidade Federal de \\ Alagoas, 57100-000 Rio Largo, AL, Brasil; ${ }^{4}$ Departamento de Fitotecnia e Zootecnia, Universidade Estadual do Sudoeste da \\ Bahia - UESB, 45083-900, Vitória da Conquista, BA, Brasil; ${ }^{5}$ Departamento de Ciências Naturais, Universidade Estadual \\ do Sudoeste da Bahia - UESB, 45083-900, Vitória da Conquista, BA, Brasil
}

Autor para correspondência: Antonio Carlos de Oliveira, e-mail: ancaol1@yahoo.com.br

\section{RESUMO}

A antracnose, causada pelo fungo Colletotrichum gloeosporioides, é a doença de pós-colheita mais importante da passicultura. Este trabalho avaliou o potencial de Agaricus blazei e Lentinula edodes nas concentrações de 20, 40 e $60 \%$ (v/v) e do acibenzolar-S-metil (ASM) a 75 e $150 \mathrm{mg} / \mathrm{L}$, aplicados isoladamente ou de forma combinada, na proteção de frutos de maracujá-azedo contra antracnose. Os frutos foram tratados (imersão, aspersão ou incorporados em cobertura de fécula de mandioca) e após $36 \mathrm{~h}$ ou $72 \mathrm{~h}$, inoculados com o fungo. A avaliação da doença foi feita pela medida da área necrosada nos frutos aos 4, 8 e 12 dias após a inoculação (dai) nos ensaios I e II e aos 3, 6 e 9 dai nos ensaios III, IV e V. Aos quatro dias após a inoculação, o tratamento com A. blazei associado à fécula de mandioca 3\% apresentou uma redução significativa da área necrosada comparado ao controle $(p=0,035)$. O L. edodes e ASM não reduziram a doença em nenhuma das concentrações e/ou épocas de avaliações realizadas. Quando os compostos foram aplicados de forma combinada nos frutos e estes não foram lavados antes da inoculação, houve uma redução significativa da área necrosada aos seis dias após a inoculação $(p=0,03)$. Entretanto, quando os frutos foram tratados, lavados e inoculados com o fungo não houve redução da doença em nenhuma das épocas avaliadas, mostrando que o modo de ação dos compostos utilizados, possivelmente, ocorre por um efeito protetor/residual atrelado a um efeito inibitório sobre C. gloeosporioides.

Palavras-chave: Colletotrichum gloeosporioides, fécula de mandioca, pós-colheita, proteção.

\begin{abstract}
Application of suspensions of Agaricus blazei, Lentinula edodes and acibenzolar-S-methyl for the reduction of anthracnose on passion fruit

Anthracnose caused by Colletotrichum gloeosporioides is one of the most important diseases of passion fruit. This study evaluated the potential of Agaricus blazei and Lentinula edodes at concentrations of 20, 40 and 60\% (v/v) and acibenzolar-S-methyl (ASM) at 75 and $150 \mathrm{mg} / \mathrm{L}$, applied alone or in combination, for protecting passion fruit against anthracnose. The fruits were treated (immersion, sprayings or in coverage of cassava starch) and after $36 \mathrm{~h}$ or $72 \mathrm{~h}$ were inoculated with the fungus. Disease assessment was done by measuring the necrotic area in the fruits at 4, 8 and 12 dai (days after inoculation) in assays I and II and 3, 6 and 9 dai in assays III, IV and V. At three days after inoculation, the treatment with $A$. blazei associated with cassava starch $3 \%$ showed a significant reduction of necrotic area compared to the control $(p=0.035)$. The L. edodes and ASM treatments did not reduce the disease in any concentration and/or periods of the evaluations. When the compounds were applied in combination and the fruits were not washed before inoculation, there was a significant reduction of necrotic area six days after inoculation $(p=0.03)$. However, when fruits were treated, washed and inoculated with the fungus there was no reduction of disease in any of the periods evaluated, showing that the mode of action of the compounds used possibly occurs by a protective/residual effect coupled with an inhibitory effect on C. gloeosporioides.
\end{abstract}

Key words: Colletotrichum gloeosporioides, cassava starch, postharvest, protection.

O maracujazeiro-azedo (Passiflora edulis Sims) é acometido porvárias doenças provocadas porvírus, bactérias, fungos, dentre outros agentes. A antracnose, causada pelo fungo Colletotrichum gloeosporioides (Penz.) Penz. \& Sacc. (teleomorfo Glomerella cingulata), é a doença de póscolheita mais importante da passicultura. As recomendações para manejo da doença não têm proporcionado um controle eficaz. Cultivares comerciais do maracujá-azedo não têm demonstrado níveis de resistência satisfatórios para controle da antracnose (Junqueira et al., 2003). Tais dificuldades para o controle da doença têm despertado um interesse para a busca de novas alternativas de manejo. A utilização de 
Aplicação de suspensões de Agaricus blazei, Lentinula edodes e...

compostos bioativos com capacidade de proteger as plantas contra doenças possibilitando a expressão de mecanismos de defesa latentes é uma estratégia que vem sendo amplamente pesquisada (El Ghaouth et al., 1994; Brisset et al., 2000; Rodrigues et al., 2006).

Extratos aquosos de basidiomicetos (cogumelos), como Agaricus blazei e Lentinula edodes vem sendo amplamente pesquisados quanto ao seu potencial na proteção de plantas contra fitopatógenos (Pacumbaba et al.; 1999; Sasaki et al., 2001; Silva et al., 2007). O composto acibenzolar-S-metil (ASM), um indutor de resistência registrado para diversas culturas, também tem promovido controle de doenças em diversas culturas (Benelli et al., 2004; Danner et al., 2008). Este trabalho teve como objetivo avaliar se Agaricus blazei, Lentinula edodes e ASM protegem frutos de maracujá-azedo contra a antracnose.

Frutos de maracujazeiro-azedo foram colhidos, de forma aleatória, de uma população de plantas pertencente ao campo experimental de Genética de Passifloras da Universidade Estadual do Sudoeste da Bahia, Campus Vitória da Conquista BA. Um isolado de C. gloeosporioides foi obtido de lesão em fruto de maracujá-azedo infectado naturalmente, conforme metodologia adotada por Silva et al. (2006). A identificação da espécie foi feita por análises morfológicas, conforme metodologia descrita por Andrade et al. (2007), e análise molecular, utilizando o primer TBCG 5' CGGAAGCCTGGGTAGGAGCG 3', específico para $C$. gloeosporioides, em conjunto com o primer conservado TB5 5' GGTAACCAGATTGGTGCTGCCTT 3', conforme descrito por Talhinhas et al. $(2002,2005)$. O fungo foi cultivado em meio batata-dextrose-agar por sete dias e uma suspensão de esporos foi obtida por raspagem de placas de Petri e adição de $10 \mathrm{~mL}$ de água destilada autoclavada, sendo a concentração $\left(10^{6}\right.$ esporos $\left./ \mathrm{mL}\right)$ ajustada em câmara de Neubauer. Para inoculação nos frutos, foi utilizado um perfurador para delimitar uma área da superfície externa do fruto, próxima ao local de inserção do fruto na planta, de 1,2 $\mathrm{cm}$ de diâmetro, a qual foi levemente raspada com bisturi. Posteriormente, alíquotas de $100 \mu \mathrm{L}$ de C. gloeosporioides foram depositadas sobre o ferimento.

O pó seco resultante de $A$. blazei e L. edodes foi obtido da empresa Fungibras Ltda., Botucatu SP, sendo suspenso em água destilada ( $1 \mathrm{~g}$ em $14 \mathrm{~mL}$ ) e posteriormente filtrado (Di Piero \& Pascholati, 2004), obtendo-se uma concentração de $100 \%(\mathrm{~m} / \mathrm{v})$. O ASM foi preparado mediante diluição em água destilada do produto comercial (Bion $\AA$ ) para atingir as concentrações de $75 \mathrm{mg} / \mathrm{L}$ e $150 \mathrm{mg} / \mathrm{L}$. A fécula de mandioca, revestimento utilizado para aumentar o tempo de prateleira dos frutos, foi preparada nas concentrações de $3 \%$ e $6 \%(\mathrm{~m} / \mathrm{v})$ conforme descrito por Lemos et al. (2006) e continham as suspensões 20, 40 e $60 \%$ (v/v) de $A$. blazei e L. edodes em sua composição.

$\mathrm{O}$ efeito de $A$. blazei (ensaio I) e $L$. edodes (ensaio II) sobre a antracnose foi avaliado sob delineamento inteiramente casualizado em esquema fatorial $4 \mathrm{x} 4$ com quatro modos de aplicação (aspersão; imersão e em revestimento com fécula de mandioca a $3 \%$ e $6 \%$ ), quatro concentrações $(0,20,40$ e $60 \%, v / v)$, quatro repetições/tratamento e 64 unidades experimentais (quatro repetições/combinação de tratamentos) para cada composto. Para o ASM (ensaio III), foi montado um ensaio sob delineamento inteiramente casualizado com imersão de frutos em três concentrações $(0,75,150 \mathrm{mg} / \mathrm{L})$ e 18 unidades experimentais (seis repetições/tratamento). Nos três ensaios, cada repetição foi representada por um fruto destacado. Decorridas $36 \mathrm{~h}$ após os tratamentos, os frutos foram inoculados com $C$. gloeosporioides.

Outros dois ensaios foram conduzidos em condições de campo utilizando-se uma combinação dos compostos. O primeiro ensaio (ensaio IV) foi montado sob delineamento inteiramente casualizado em esquema fatorial $2 \times 6$ contendo dois tratamentos [aspersão de mistura das suspensões de A. blazei, L. edodes e do ASM nas concentrações de $50 \%$ $(\mathrm{v} / \mathrm{v}), 50 \%(\mathrm{v} / \mathrm{v})$ e $100 \mathrm{mg} / \mathrm{L}$, respectivamente, e água (controle)] e seis genótipos (UESB-B29, UESB-C16, UESB-E10, UESB-A24, UESB-D22 e UESB-C18)], os quais apresentavam um ano de idade. Foram 4 repetições/ tratamento e 48 unidades experimentais. Os tratamentos foram pulverizados duas vezes, com intervalo de 15 dias entre as aplicações. Decorridas 72 h após a segunda pulverização, os frutos foram coletados e não lavados antes da inoculação do C. gloeosporioides. O último ensaio em condições de campo (ensaio V) foi conduzido de forma similar ao primeiro com a diferença de que, após $72 \mathrm{~h}$ da segunda pulverização, os frutos foram coletados e lavados em água destilada antes da inoculação com o fungo. Nestes dois ensaios cada repetição foi representada por um fruto não-destacado tratado.

A avaliação da antracnose foi feita medindo-se a área necrosada (multiplicação de duas medidas diametralmente opostas da lesão) aos 4, 8 e 12 dai (dias após a inoculação) no ensaio I e II; aos 3, 6 e 9 dai nos ensaios III, IV e V. Os resultados médios da área necrosada foram submetidos à ANOVA Fatorial (ensaios I, II, IV e V) ou a um critério (Kruskal-Wallis) (ensaios III), ambos com $\alpha=0,05 \mathrm{e}$, posteriormente, a testes de comparação de médias ScottKnott $(\alpha=0,05)$. Para as transformações de dados e testes estatísticos, empregou-se o software Bioestat v4.0 (Ayres et al., 2005).

No ensaio I foi detectada uma diferença significativa entre os métodos de aplicação do A. blazei aos 4 dai ( $p=$ 0,035 ) (Figura 1A), sendo que a cobertura com a fécula de mandioca a $3 \%$ resultou em área necrosada $(1,85 \pm 0,2)$ estatisticamente menor que no controle $(2,23 \pm 0,3)$. Não houve diferença entre as concentrações da suspensão de $A$. blazei $(p=0,834)$. Para as demais épocas de avaliação de A. blazei e em todas as avaliações de L. edodes (ensaio II) não houve diferença significativa entre modos de aplicação, concentração dos compostos bioativos e interação entre esses dois fatores (Figura 1 A-B). Resultados similares a estes foram obtidos por Cia (2005), quando frutos de mamão submetidos ao tratamento com suspensões de A. blazei e 
A

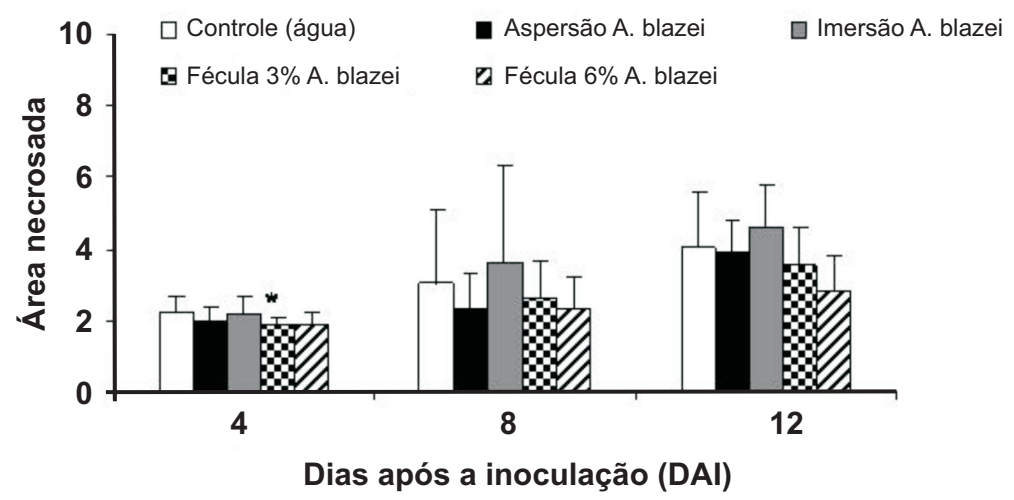

B

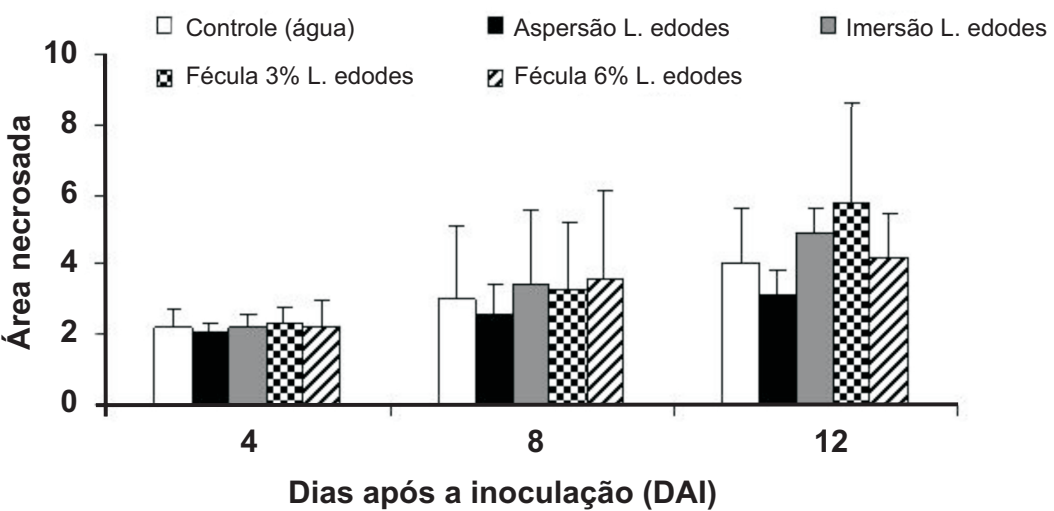

FIGURA 1 - Efeito de suspensões de Agaricus blazei (A) e Lentinula. edodes (B) no tamanho das lesões da antracnose, causada por Colletotrichum gloeosporioides, em frutos de maracujá-azedo. Não houve diferença entre as concentrações $(20 \%, 40 \%$ e $60 \%)$ das suspensões. O asterisco (*) indica diferença significativa do tratamento em relação ao controle pelo teste Scott-Knott a $5 \%$ de significância.

L. edodes na concentração de $5 \%(\mathrm{v} / \mathrm{v})$ e posteriormente inoculados com $C$. gloeosporioides não apresentaram redução das lesões, pois possivelmente não houve estímulo de respostas de defesa nos frutos ou a concentração foi insuficiente para inibir o crescimento do patógeno.

Os resultados médios da área necrosada em frutos destacados tratados com ASM (75 e 150 mg/L) por imersão (ensaio III) não foram estatisticamente diferentes do controle, independente da época de avaliação $(p=0,057)$ (Figura 2). A ineficiência do ASM em induzir resistência pós-colheita já havia sido relatada em fruteiras como banana, contra $F$. oxysporum f. sp. cubense, causador do 'mal-do-Panamá' (Querino et al., 2005) e mesmo para o maracujá-azedo contra C. gloeosporioides, quando aspergidos previamente na concentração de $100 \mathrm{mg} / \mathrm{L}$ (Almeida, 2006). No presente ensaio, foram avaliadas concentrações menor $(75 \mathrm{mg} / \mathrm{L}) \mathrm{e}$ maior $(150 \mathrm{mg} / \mathrm{L})$ do composto bioativo, além de empregar método de aplicação (imersão), sendo obtidos resultados similares àqueles encontrados por Almeida (2006).

Os resultados do ensaio IV (frutos não lavados antes da inoculação) mostraram um efeito significativo entre o tratamento com a mistura das suspensões de A. blazei, $L$. edodes e do ASM e o controle $(p=0,03)$ aos 6 d.a.i. (Tabela 1). Para o ensaio V (frutos lavados antes da inoculação), não foi detectado efeito significativo entre os tratamentos em nenhuma das épocas avaliadas ( 3 d.a.i., $p=0,18 ; 6$ d.a.i., $p$ $=0,34 ; 9$ d.a.i., $p=0,89)$. Entretanto, o efeito do genótipo foi significativo aos $3(p<0,001)$ e $9(p=0,03)$ dai, evidenciando que a resposta dos mesmos aos tratamentos difere entre si (Tabela 2). Portanto, a adoção da prática de lavar os frutos antes de desafiá-los com o fungo suporta a hipótese que o modo de ação das suspensões utilizadas se

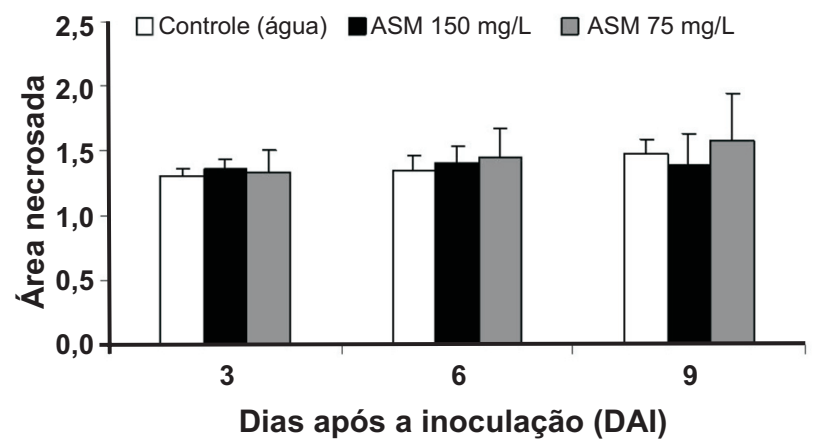

FIGURA 2 - Efeito do ASM no tamanho das lesões da antracnose, causada por Colletotrichum gloeosporioides, em frutos de maracujá-azedo Não foi observada diferença estatística entre os tratamentos nas diferentes épocas avaliadas.

Tropical Plant Pathology 36 (1) January - February 2011 
Aplicação de suspensões de Agaricus blazei, Lentinula edodes e...

TABELA 1 - Efeito da aplicação combinada de suspensões de Agaricus blazei, Lentinula. edodes e do ASM no tamanho das lesões (média \pm desvio-padrão) da antracnose em frutos de maracujá-azedo não lavados antes da inoculação artificial de Colletotrichum gloeosporioides

\begin{tabular}{|c|c|c|c|c|}
\hline \multirow[b]{2}{*}{ Tratamentos } & \multirow[b]{2}{*}{ Genótipo } & \multicolumn{3}{|c|}{ Épocas de avaliação } \\
\hline & & 3 dai & 6 dai & 9 dai \\
\hline Controle & UESB- $B 29$ & $1,703 \pm 0,001$ & $1,862 \pm 0,081$ & $1,984 \pm 0,148$ \\
\hline Mistura & UESB-B29 & $1,705 \pm 0,001$ & $1,885 \pm 0,051^{*}$ & $2,058 \pm 0,231$ \\
\hline Controle & UESB-C16 & $1,715 \pm 0,021$ & $1,885 \pm 0,125$ & $2,103 \pm 0,253$ \\
\hline Mistura & UESB-C16 & $1,704 \pm 0,000$ & $1,866 \pm 0,051^{*}$ & $1,895 \pm 0,067$ \\
\hline Controle & UESB-E10 & $1,704 \pm 0,004$ & $1,876 \pm 0,034$ & $1,897 \pm 0,038$ \\
\hline Mistura & UESB-E10 & $1,705 \pm 0,001$ & $1,860 \pm 0,066^{*}$ & $1,705 \pm 0,001$ \\
\hline Controle & UESB- $A 24$ & $1,703 \pm 0,001$ & $1,824 \pm 0,042$ & $1,887 \pm 0,048$ \\
\hline Mistura & UESB- $A 24$ & $1,704 \pm 0,001$ & $1,831 \pm 0,051^{*}$ & $1,969 \pm 0,111$ \\
\hline Controle & UESB-D22 & $1,702 \pm 0,001$ & $1,942 \pm 0,028$ & $2,220 \pm 0,240$ \\
\hline Mistura & UESB-D22 & $1,704 \pm 0,041$ & $1,705 \pm 0,001 *$ & $1,905 \pm 0,090$ \\
\hline Controle & UESB-C18 & $1,703 \pm 0,001$ & $1,830 \pm 0,035$ & $2,202 \pm 0,401$ \\
\hline Mistura & UESB-C18 & $1,703 \pm 0,001$ & $1,823 \pm 0,038^{*}$ & $2,027 \pm 0,367$ \\
\hline
\end{tabular}

$\left({ }^{*}\right)$ indica diferença estatística em relação ao respectivo controle pelo teste Scott-Knott a $\left.\alpha=0,05\right)$. d.a.i. $=$ dias após a inoculação.

TABELA 2 - Efeito da aplicação combinada de suspensões de Agaricus blazei, Lentinula edodes e do ASM no tamanho das lesões (média \pm desvio-padrão) da antracnose em frutos de maracujá-azedo previamente lavados antes da inoculação artificial de Colletotrichum gloeosporioides

\begin{tabular}{|c|c|c|c|c|}
\hline \multirow[b]{2}{*}{ Tratamentos } & \multirow[b]{2}{*}{ Genótipos } & \multicolumn{3}{|c|}{ Épocas de avaliação } \\
\hline & & 3 dai & 6 dai & 9 dai \\
\hline Controle & UESB-B29 & $2,16 \pm 0,01$ & $2,33 \pm 0,23$ & $3,74 \pm 2,40$ \\
\hline Mistura & UESB-B29 & $2,05 \pm 0,00$ & $2,18 \pm 0,05$ & $4,10 \pm 2,08 *$ \\
\hline Controle & UESB-C16 & $2,05 \pm 0,00$ & $2,02 \pm 0,01$ & $2,31 \pm 0,08$ \\
\hline Mistura & UESB-C16 & $2,05 \pm 0,00$ & $2,08 \pm 0,01$ & $2,24 \pm 0,01$ \\
\hline Controle & UESB-E10 & $2,18 \pm 0,06$ & $2.18 \pm 0,06$ & $2,31 \pm 0,09$ \\
\hline Mistura & UESB-E10 & $2,19 \pm 0,09 *$ & $2,25 \pm 0,19$ & $2,29 \pm 0,16$ \\
\hline Controle & UESB- $A 24$ & $2,08 \pm 0,05$ & $2,22 \pm 0,19$ & $2,51 \pm 0,24$ \\
\hline Mistura & UESB- $A 24$ & $2,05 \pm 0,00$ & $2,22 \pm 0,09$ & $2,29 \pm 0,14$ \\
\hline Controle & UESB-D22 & $2,05 \pm 0,00$ & $2,13 \pm 0,06$ & $2,42 \pm 0,14$ \\
\hline Mistura & UESB-D22 & $2,05 \pm 0,00$ & $2,19 \pm 0,05$ & $2,45 \pm 0,15$ \\
\hline Controle & UESB-C18 & $2.05 \pm 0,00$ & $2,12 \pm 0,01$ & $2,27 \pm 0,13$ \\
\hline Mistura & UESB-C18 & $2,05 \pm 0,00$ & $2,18 \pm 0,07$ & $2,42 \pm 0,29$ \\
\hline
\end{tabular}

$(*)$ indica diferença estatística em relação ao respectivo controle pelo teste Scott-Knott a $\alpha=0,05$. d.a.i. $=$ dias após a inoculação

dá, possivelmente, por um efeito protetor atrelado ao efeito inibitório de cada um dos componentes da mistura sobre $C$. gloeosporioides, validando o que foi detectado em testes preliminares de efeito antimicrobiano in vitro de $A$. blazei, L. edodes e ASM sobre o fungo (dados não mostrados). $\mathrm{O}$ efeito de genótipo observado neste estudo é um aspecto importante a ser considerado uma vez que a seleção de genótipos que apresentem respostas de defesa frente à aplicação de elicitores pode se constituir em ferramenta útil nos programas de melhoramento genético.

Embora não se tenha utilizado lote de frutos não inoculados (controle), com a finalidade de determinar a eventual existência e magnitude de infecções quiescentes de C. gloeosporioides, em nenhum dos ensaios foram observados sintomas da antracnose que não estivessem circunscritas a área do fruto previamente delimitada para a realização da inoculação artificial do fungo. A ausência de infecções latentes pode ser interpretada como sendo decorrente das baixas temperaturas ambientes em Vitória da Conquista e/ou aos tratos horticulturais de rotina, que incluíram a aplicação de fungicidas no campo experimental.

Algumas metodologias de aplicação de indutores de resistência em frutos são comumente utilizadas, tais como imersão ou aspersão dos mesmos (Romanazzi et al., 2002; Dantas et al., 2004). A deposição de fécula de mandioca, na superfície de frutos, empregada no presente estudo, foi utilizada em pós-colheita para ampliar o tempo de prateleira dos frutos (Damasceno et al., 2003; Lemos et al., 2006) e não tinha sido, até então, testada em associação com compostos bioativos, com vistas a estudar efeito indutor e/ou protetor dos mesmos. 
D.S.O. Coqueiro et al.

A busca da capacidade de proteger frutos ainda em condições de campo a patógenos de pós-colheita se justifica, tendo em vista os relatos da ação do ASM induzindo resistência contra podridões acarretada pelo fungo Fusarium (Huang, 2000). O screening de compostos bioativos que induzem resistência e/ou proteção pode ser otimizado empregando-se a aplicação dos mesmos combinadamente, como no presente estudo.

Portanto, considerando o caráter exploratório inicial deste trabalho que visou encontrar compostos bioativos no controle da antracnose do maracujá-azedo, é importante que estudos adicionais sejam conduzidos a fim de se comparar o efeito das suspensões de A. blazei, L. edodes e do ASM com fungicidas já utilizados no controle da antracnose do maracujá-azedo para avaliação do grau de eficiência, bem como da relação custo-benefício.

\section{AGRADECIMENTOS}

Ao Dr. Luiz Carlos Cordeiro de Almeida (CEPLAC, Ilhéus BA) pelas informações pertinentes na montagem de ensaios contendo tratamento de frutos com fécula de mandioca. A Alanna C. F. Pereira pelo valioso auxílio no laboratório. À Fundação de Amparo a Pesquisa do Estado da Bahia - FAPESB pela bolsa de estudo de Iniciação Científica, vigência 2006-2007, concedida à primeira autora.

\section{REFERÊNCIAS BIBLIOGRÁFICAS}

Ayres M, Ayres Jr M, Ayres DN, Santos AS (2005) BioEstat 4.0: aplicações estatísticas nas áreas das Ciências Biológicas e Médicas. Pará. Imprensa Oficial do Estado de Pará, Sociedade Civil Mamirauá, MCT.

Almeida LCC, Coelho RSB (2006) Efeito de indutores químicos no controle da antracnose do maracujá amarelo pós-colheita. Fitopatologia Brasileira 31:318.

Andrade EM, Uesugi CH, Ueno B, Ferreira MASV (2007) Caracterização morfocultural e molecular de isolados de Colletotrichum gloeosporioides patogênicos ao mamoeiro. Fitopatologia Brasileira 31:21-31.

Benelli AIH, Denardin ND, Forcelini CA (2004) Ação do acibenzolar-S-metil aplicado em tubérculos e plantas de batata contra canela preta, incitada por Pectobacterium carotovorum subsp. atrosepticum atípica. Fitopatologia Brasileira 29:263-267.

Brisset M, Cesbron S, Thomson SV, Paulin J (2000) AcibenzolarS-methyl induces the accumulation of defense-related enzymes in apple and protects from fire blight. European Journal of Plant Pathology 106:529-536.

Cia P (2005) Avaliação de agentes bióticos e abióticos na indução de resistência e no controle pós-colheita da antracnose (Colletotrichum gloeosporioides) em mamão (Carica papaya). Tese de Doutorado. Universidade de São Paulo, ESALQ. Piracicaba, SP.

Damasceno S, Oliveira PVS, Moro E.; Macedo Jr EK, Lopes MC,
Vicentini NM (2003) Efeito da aplicação de película de fécula de mandioca na conservação pós-colheita de tomate. Ciência e Tecnologia de Alimentos 23:377-380.

Danner MA, Sasso SAZ, Medeiros JGS, Marchese AJ, Mazaro SM (2008) Indução de resistência à podridão-parda em pêssegos pelo uso de eliciadores em pós-colheita. Pesquisa Agropecuária Brasileira 43:793-799.

Dantas SAF, Oliveira SMA, Bezerra Neto E, Coelho RSB, Silva RLX (2004) Indutores de resistência na proteção do mamão contra podridões pós-colheita. Summa Phytopathologica 30:314-319.

Di Piero RM, Pascholati SF (2004) Indução de resistência em plantas de pepino contra Colletotrichum lagenarium pela aplicação de extratos de basidiocarpos de Lentinula edodes e de Agaricus blazei. Summa Phytopathologica 30:243-250.

El Ghaouth AJ, Wilson C, Benhamou N (1994) Ultrastructural and cytochemical aspects of the effect of chitosan on decay of bell pepper fruit. Physiological and Molecular Plant Pathology 44:417-432.

Huang Y, Deverall BJ, Tang WH, Wang W, Wu FW (2000) Foliar application of acibenzolar-S-methyl and protection of postharvest rock melons and Hami melons from disease. European Journal of Plant Pathology 106:651-656.

Junqueira NTV, Anjos JRN, Silva APO, Chaves SC, Gomes AC (2003) Reação às doenças e produtividade de onze cultivares de maracujá-azedo cultivadas sem agrotóxico. Pesquisa Agropecuária Brasileira 38:1005-1010.

Lemos OL, Rebouças TNH, São José AB, Vila MTR, Silva KS (2006) Utilização de biofilme comestível na conservação de pimentão 'Magali r' em duas condições de armazenamento. Bragantia 66:693-699.

Pacumbaba RP, Beyl CA, Pacumbaba RO (1999) Shiitake mycelial leachate suppresses growth of some bacterial species and symptoms of bacterial wilt of tomato and lima bean in vitro. Plant Disease 81:20-23.

Querino CMB, Laranjeira D, Coelho RSB, Matos AP (2005) Efeito de dois indutores de resistência sobre a severidade do maldo-Panamá. Fitopatologia Brasileira 30:239-243.

Rodrigues AAC, Bezerra Neto E, Coelho RSB (2006) Indução de resistência a Fusarium oxysporum f. sp. tracheiphilum em caupi: eficiência de indutores abióticos e atividade enzimática elicitada. Fitopatologia Brasileira 31:492-499.

Romanazzi G, Nigro F, Ippolito A, Di Venere D, Salerno M (2002) Effects of pre- and postharvest chitosan treatments to control storage grey mold of table grapes. Journal of Food Science 67:1862-1867.

Sasaki SH, Linhares REC, Nozawa CM, Montalván R, PaccolaMeirelles LD (2001) Strains of Lentinula edodes suppress growth of phytopathogenic fungi and inhibit alagoas serotype of vesicular stomatitis virus. Brazilian Journal of Microbiology 32:52-55.

Silva RF, Pascholati SF, Bedendo IP (2007) Indução de resistência em tomateiro por extratos aquosos de Lentinula edodes e Agaricus blazei contra Ralstonia solanacearum. Fitopatologia Brasileira 32:189-196.

Silva KS, Rebouças TNH, Lemos OL, Bonfim MP, Bomfim AA, Esquivel GL, Barreto APP, São José AR, Dias NO, Tavers GM (2006) Patogenicidade causada pelo fungo Colletotrichum gloeosporioides (Penz.) em diferentes espécies frutíferas. Revista 
Aplicação de suspensões de Agaricus blazei, Lentinula edodes e...

Brasileira de Fruticultura 28:131-133.

Talhinhas P, Sreenivasaprasad S, Neves-Martins J, Oliveira H (2005) Molecular and phenotypic analyses reveal the association of diverse Colletotrichum acutatum groups and a low level of C. gloeosporioides with olive anthracnose. Applied and
Environmental Microbiology 71:2987-2998.

Talhinhas P, Sreenivasaprasad S, Neves-Martins J, OliveiraH(2002) Genetic and morphological characterization of Colletotrichum acutatum causing anthracnose of lupins. Phytopathology 92:986996. 